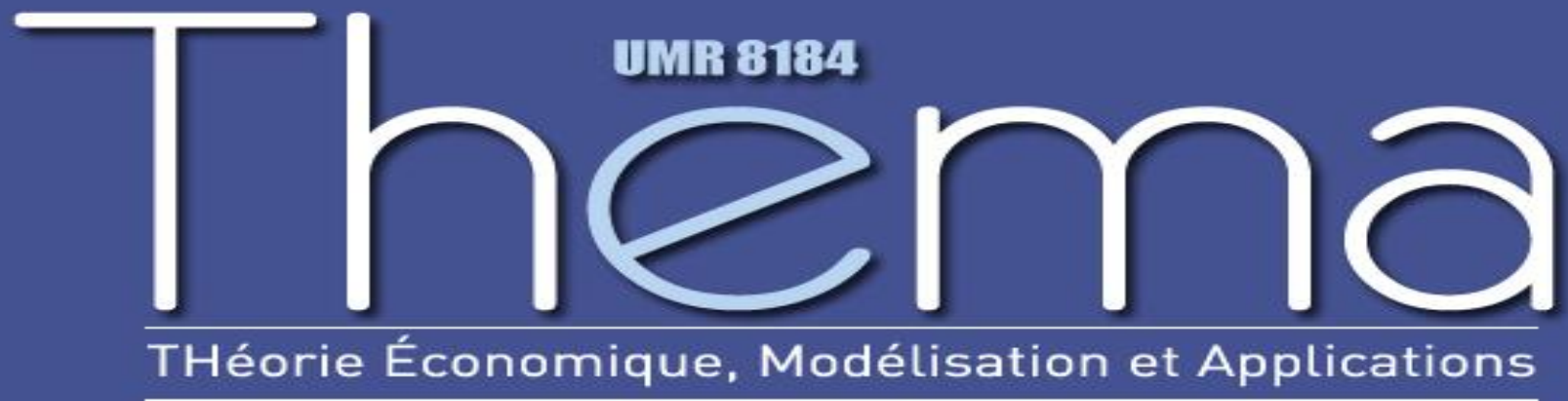

Thema Working Paper $n^{\circ} 2012-25$

Université de Cergy Pontoise, France

Are Southeast Asian Real Exchange Rates Mean Reverting?

Frédérique Bec Songlin zeng

February, 2012 


\title{
Are Southeast Asian Real Exchange Rates Mean Reverting?
}

\author{
Frédérique BEC* $\quad$ Songlin $\mathrm{ZENG}^{\dagger}$
}

February 2012

\begin{abstract}
Since the late nineties, both theoretical and empirical analysis devoted to the real exchange rate suggest that their dynamics might be well approximated by nonlinear models. This paper examines this possibility for post-1970 monthly ASEAN-5 data, extending the existing research in two directions. First, we use recently developed unit root tests which allow for more flexible nonlinear stationary models under the alternative than the commonly used Self-Exciting Threshold or Exponantial Smooth Transition AutoRegressions. Second, while different nonlinear models survive the mis-specification tests, a Monte Carlo experiment from generalized impulse response functions is used to compare their relative relevance. Our results i) support the nonlinear mean-reverting hypothesis, and hence the Purchasing Power Parity, in most of the ASEAN-5 countries and ii) point to the Multiple Regime-Logistic Smooth Transition and the Exponantial Smooth Transition AutoRegression models as the most likely data generating processes of these real exchange rates.
\end{abstract}

Keywords: Purchasing Power Parity, Nonlinear Threshold Models, Southeast Asian Real Exchange Rates.

JEL classification: C12, C22, F31.

${ }^{*}$ Thema, University of Cergy-Pontoise, F-95000 Cergy-Pontoise, and CREST, France. E-mail: bec@ensae.fr

†Thema, University of Cergy-Pontoise, F-95000 Cergy-Pontoise, and Department of Economics, ESSEC, France. E-mail: songlin.zeng@u-cergy.fr 


\section{Introduction}

Over the last decade, the empirical unit root and/or cointegration tests of the long run Purchasing Power Parity relationship have shifted from a linear towards a nonlinear setup ${ }^{1}$. Basically, the general equilibrium models developed by e.g. Dumas [1992], Sercu, Uppal and Van Hulle [1995], or Berka [2004] imply a nonlinear dynamics for the real exchange rate in presence of trading costs. The underlying idea is that international trade in goods occurs only when the gain expected from the home and foreign price differential is large enough to offset trading costs. Once trade takes place across countries, it induces changes in home and foreign prices which bring the real exchange rate back into the area where international arbitrage is not profitable anymore. The latter area is a non-arbitrage zone where the real exchange rate behaves like a non-stationary process. Nevertheless, since any price differential larger than the trading costs will trigger corrective international trade, the real exchange rate process is globally stationary or stable. Due to the random-walk like dynamics of the real exchange in the inner regime, most of the observations belong to the latter: this in turn explains the failure of linear unit root tests to detect the global stationarity of the process. Hence, specific unit root tests have been recently developed in order to consider a nonlinear stationary under the alternative hypothesis (see e.g. Enders and Granger [1998], Lo and Zivot [2001], Kapetanios, Shin and Snell [2003], Bec, Ben Salem and Carrasco [2004], Park and Shintani [2005], Bec, Guay and Guerre [2008a] or Bec, Ben Salem and Carrasco [2010]).

The empirical relevance of these theoretical implications has been explored by a large number of studies for the main OECD countries, using either discontinuous or smooth threshold autoregressive models. For instance, the empirical analysis by Michael, Nobay and Peel [1997], Obstfeld and Taylor [1997], Kilian and Taylor [2003], Taylor, Peel and Sarno [2001], Bec et al. [2004], Bec, Rahbek and Shephard [2008b] or Bec et al. [2010] provide some support to the PPP relation from multiple

\footnotetext{
${ }^{1}$ See Rogoff [1996] for a comprehensive survey of the literature in the linear framework, and Balke and Fomby [1997] for an introduction to the rationale of the nonlinear modelling of the real exchange rates.
} 
regime models for real exchange rate data. Nevertheless, only a few papers have explored this issue for Asian exchange rates data so far. Yet, as stressed by Kim, Kim and Oh [2009], the PPP assumption has a special meaning to Southeast Asian countries. Actually, the countries belonging to the Association of Southeast Asian Nations (ASEAN hereafter) aim to create an ASEAN Economic Community by 2015, which could be a first step towards a monetary union ${ }^{2}$. Hence, the PPP relation could prove very useful to choose the optimal common currency for the potential currency union among Southeast Asian countries.

Most of the earlier papers investigating the possible nonlinear PPP relationship for Southeast Asian data have done so by introduting the possibility of structural breaks under the stationary alternative, either using time series techniques (see e.g. Aggarwal, Montanes and Ponz [2000] or Zurbruegg and Allsopp [2004]) or panel data econometrics (as in Wu, Tsai and Chen [2004]). They generally find that the unit root null rejection rate is larger in the structural break analysis than in the standard linear setup. More recently, Kim et al. [2009] also find support to the PPP relationship in the Southeast Asian real exchange rates from time-varying cointegration coefficients approach. More precisely, their results are compatible with the PPP for Indonesia, Korea, Philippines and Singapore when the base currency is the U.S. Dollar.

Concurrently, but to a somewhat lesser extent, unit root tests against a thresholdtype nonlinear alternative have been explored for these real exchange rate data. First, Liew, Baharumshah and Chong [2004] apply the unit root test developed by Kapetanios et al. [2003] for a nonlinear Exponential Smooth Transition AutoRegression (ESTAR) stationary alternative to 11 Asian real exchange rates and reject the null for eight U.S. Dollar based rates data. More recently, Choi, Kim and Kim [2011] use the inf - $t$ unit root test proposed in Park and Shintani [2005] against various nonlinear stationary alternatives including Threshold AutRegression (TAR) and Logistic Smooth Transition AutoRegression (LSTAR) models. When the U.S. dollar is the numeraire currency, they find that $63 \%$ of the real exchange rates of Southeast Asian currencies are consistent with nonlinear stationary

\footnotetext{
${ }^{2}$ Of course, the recent turmoil in the Euro area is closely scrutinized by the ASEAN members and the common currency project is accordingly considered as premature.
} 
processes. Our contribution to this strand of empirical research is twofold.

First, we enlarge the set of unit root tests used in previous works to cover a wider class of relevant nonlinear stationary models under the alternative for the Southeast Asian real exchange rates. Actually, we implement the unit root tests developed by Bec et al. [2010] and Bec et al. [2008a]. The former is built against a Multiple Regime Logistic Smooth Transition AutoRegression (MR-LSTAR) model under the alternative hypothesis. As shown by the authors, the MR-LSTAR model has the desirable property that it allows for both ESTAR-type and SETAR-type dynamics. Yet, even though the ESTAR model is often considered as the smooth transition analogue of the SETAR model, the former does not nest the latter. Unfortunately, neither the discontinuous nor the continuous adjustment cases can be ruled out a priori on theoretical grounds. On the other hand, the latter unit root test developed by Bec et al. [2008a] is shown by the authors to have power against any stationary alternative, including the Autoregressive Conditional Root (ACR) model that we will also consider. Indeed, this model may be viewed as an appealing alternative to the threshold autoregressive class of models retained in the papers cited above since it does not require a fixed threshold.

Second, for the real exchange rate series which succeed in rejecting the unit root null, we will estimate four nonlinear candidates (SETAR, ESTAR, MR-LSTAR and ACR) and use the approach presented in Lo [2008] to assess their relative relevance. Actually, based on the simulation techniques developed in Koop, Pesaran and Potter [1996], Lo [2008] proposes a measure of the mean bias in the impulse responses due to model mis-specification. To sum up the underlying idea, if a particular nonlinear model is the true data generating process, then the corresponding constrained linear version of it should be able to capture the unconditional generalized impulse response function. Consequently, this mean bias should be zero.

Finally, these recent developments in nonlinear times series econometrics allow to shed new light on the behaviour of Southeast Asian real exchange rates. For this analysis, we use monthly post-1970 Asian real exchange rate data vis-a-vis the US Dollar. Our results confirm that standard ADF unit root tests basically fail to reject the null whereas nonlinear unit root tests reject it at the $5 \%$-level is four out 
of five cases, namely Indonesia, Malaysia, Philippines, Thailand and South Korea and at the 10\%-level in the last one, Singapore. For these countries, the mean bias of the simulated generalized impulse response functions clearly point to the MR-LSTAR and ESTAR models as the most likely true DGPs, hence confirming Lo [2008] conclusions for the US-G6 real exchange rates.

The paper is organized as follows. Section 1 presents the four nonlinear models under consideration and the mean bias measure used to assess their relevance. Section 2 presents the data and the empirical results: the preliminary unit root and linearity tests, the estimated nonlinear models and their comparison based on the general impulse response functions. Section 3 concludes.

\section{Methodology}

\subsection{The Nonlinear Time Series Models Under Considera- tion}

In this paper, we will focus exclusively on models which are able to capture the kind of dynamics discussed in the section above. Hence, the four models considered below allow for a central non-arbitrage area corresponding to small absolute values of the real exchange rate, surrounded by arbitrage areas where the departures to the purchasing power parity, i.e. the absolute values of the real exchange rate are large. The main difference between these models lies in the characterization of the transition function between regimes. To fix ideas, let us first consider the following general $y_{t}$ process, written in an error correction form as follows:

$$
\Delta y_{t}=\sum_{i=1}^{p-1} \psi_{i} \Delta y_{t-i}+f\left(s_{t}\left(y_{t-1}\right), y_{t-1}\right)+\varepsilon_{t}
$$

where the sequence $\varepsilon_{t}$ is assumed to be i.i.d $N\left(0, \sigma^{2}\right)$ and $f\left(s_{t}\left(y_{t-1}\right), y_{t-1}\right)$ is a regime-dependent function of the lagged endogenous value, $y_{t-1}$, and of a state variable $s_{t}\left(y_{t-1}\right)$ which also depends on $y_{t-1}$. In the benchmark linear $\operatorname{AR}(p)$ model, the $f($.$) function reduces to:$

$$
f\left(s_{t}\left(y_{t-1}\right), y_{t-1}\right) \equiv s_{t}\left(\mu+\phi y_{t-1}\right) \quad \text { with } s_{t}=1, \forall t
$$


Note that the state variable $s_{t}$ is set to 1 for all $t$ because there is only one regime in the linear AR model.

One of the first nonlinear models considered to capture the real exchange rates dynamics implied by the presence of trading costs (see e.g. Balke and Fomby [1997], Obstfeld and Rogoff [2000] or Bec et al. [2004]) is the SETAR model, which in equation (1), corresponds to the following regime-dependent function:

$$
\begin{gathered}
f\left(s_{t}\left(y_{t-1}\right), y_{t-1}\right) \equiv s_{t}^{\ell}\left[-\mu_{1}+\phi_{1} y_{t-1}\right]+\left(s_{t}^{i}\right)\left[\mu_{2}+\phi_{2} y_{t-1}\right]+s_{t}^{u}\left[\mu_{1}+\phi_{1} y_{t-1}\right] \\
\text { with } s_{t}^{\ell}=1_{y_{t-1}<-\lambda}, s_{t}^{i}=1_{\left|y_{t-1}\right| \leq \lambda} \text { and } s_{t}^{u}=1_{y_{t-1}>\lambda} .
\end{gathered}
$$

Here, the discontinuity is implied by the switching between regimes: since $s_{t}\left(y_{t-1}\right)$ is zero-one valued, it is not continuous. The trading cost is represented by threshold parameter, $\lambda$, which determines the regime of the real exchange rate. The dynamics outside the central area is governed by $\mu_{1}$ and $\phi_{1}$. As shown in Bec et al. [2004] or Bec and Rahbek [2004], a sufficient condition for the ergodicity of the $y_{t}$ process given by equation (3) is that the roots of the characteristic polynomial associated to the outer regime lie outside the unit circle. The inner regime dynamics may be characterized by a unit root or an explosive root without altering this result.

Nevertheless, as discussed in the introduction, some theoretical models suggest a smooth adjustment of the real exchange rate (see Dumas [1992] or Berka [2004]). This kind of dynamics may be captured by the ESTAR model, popularized by Michael et al. [1997] and extensively applied since their publication. For equation (1) to define an ESTAR model, the $f($.$) function has to specialize as follows:$

$f\left(s_{t}\left(y_{t-1}\right), y_{t-1}\right) \equiv s_{t}\left[\mu_{1}+\phi_{1} y_{t-1}\right]+\left(1-s_{t}\right)\left[\mu_{2}+\phi_{2} y_{t-1}\right], \quad$ with $s_{t}=1-\exp \left(-\gamma y_{t-1}^{2}\right)$.

Here, $s_{t}$ represents the probability for the real exchange rate to lie in the outer regime. When $y_{t-1}$ tends to infinity, the probability of being in the outer regime, $s_{t}$, goes to $1 . \gamma$ is a parameter which governs the transition speed between the two regimes. Note that as $\gamma$ tends to infinity, the ESTAR model reduces to the linear AR model. Nevertheless, the ESTAR model does not include the SETAR model as a special case. Kapetanios et al. [2003] (hereafter KSS) have developed a test specifically designed for such a stationary nonlinear alternative, simplifying 
the model defined in equations (1) and (4) by further assuming a unit root in the inner regime, or $\phi_{2}=0$.

Although smooth adjustment is allowed by the ESTAR model, Bec et al. [2010] stress that one cannot not rule out a discontinuous adjustment as in the SETAR model from theoretical grounds. For this reason, they develop a general MRLSTAR model which can fit ESTAR-type dynamics while also containing the SETAR model as a special case. The MR-LSTAR model corresponds to equation (1) with

$$
f\left(s_{t}\left(y_{t-1}\right), y_{t-1}\right) \equiv s_{t}^{\ell}\left[-\mu_{1}+\phi_{1} y_{t-1}\right]+\left(s_{t}^{i}\right)\left[\mu_{2}+\phi_{2} y_{t-1}\right]+s_{t}^{u}\left[\mu_{1}+\phi_{1} y_{t-1}\right]
$$

with $s_{t}^{\ell}=\left[1+\exp \left(\gamma\left(y_{t-1}+\lambda\right)\right)\right]^{-1}, s_{t}^{i}=1-s_{t}^{\ell}-s_{t}^{u}$ and $s_{t}^{u}=\left[1+\exp \left(-\gamma\left(y_{t-1}-\lambda\right)\right)\right]^{-1}$, where $\lambda$ and $\gamma$ denote again the threshold and the transition speed parameters respectively. When $y_{t-1}$ goes to $-\infty, s_{t}^{\ell}$ goes to unity while $s_{t}^{u}$ goes to zero, so that the MR-LSTAR dynamics are determined by $\phi_{1}$. Moreover, as the speed parameter $\gamma$ tends to $\infty$, the MR-LSTAR model reduces to a SETAR model since $s_{t}^{\ell} \rightarrow 1\left(y_{t-1}<-\lambda\right)$ and $s_{t}^{u} \rightarrow 1\left(y_{t-1}>\lambda\right)$. Bec et al. [2010] propose a unit root test against the alternative given by equations (1) and (5) which amounts to test the null $\mu_{1}=\phi_{1}=\mu_{2}=\phi_{2}$ in equation (5) and is shown to be more powerful than the KSS test.

While these above models assume a fixed threshold value, the Autoregressive conditional root (ACR) model developed by Bec et al. [2008b] relaxes this assumption. Beside, the ACR model still allows for regime switching between stationary and non-stationary epochs, with a switching function depending on the magnitude of the lagged endogenous variable. Hence, it provides an appealing alternative model for the real exchange rate dynamics. In the ACR model, the $f($.$) function$ in equation (1) is given by:

$$
\begin{gathered}
f\left(s_{t}\left(y_{t-1}\right), y_{t-1}\right) \equiv s_{t}\left(\phi_{1} y_{t-1}\right)+\left(1-s_{t}\right)\left(\phi_{2} y_{t-1}\right) \\
\text { with } s_{t}=1 \text { or } 0
\end{gathered}
$$

where $s_{t}$ is governed by $P\left(s_{t}=1 \mid y_{t-1}, \varepsilon_{t}\right)=\frac{\exp \left(a+b\left|y_{t-1}\right|^{0.5}\right)}{1+\exp \left(a+b\left|y_{t-1}\right|^{0.5}\right)}$. The essential requirement for the conditional probability $P\left(s_{t}=1 \mid y_{t-1}, \varepsilon_{t}\right)$, is that it tends to one 
as $\left|y_{t-1}\right|$ tends to infinity in addition to it being a function of $y_{t-1}$. For this logistic type transition function, different combinations of $a$ and $b$ determine the shape of transition. Within this equilibrium correction form of the ACR model, the unit root test amounts to test the null $\phi_{2}=0$. The adaptive unit root test developed in Bec et al. [2008a] is shown to have a good power against this kind of alternative.

\subsection{Model selection from the general impulse response func- tion mean bias}

Since the four nonlinear models discussed above are compatible with the behavior of real exchange rates as predicted by the economic theory in presence of trading costs, we would like to compare them so as to determine which one is the most likely data generating process for Southeast Asian data. Since the MR-LSTAR includes the SETAR model as special cases, looking at the shape of the estimated transition function might give some hints for these two models comparison. Unfortunately, the SETAR constrained version cannot be tested directly against the general MRLSTAR on statistical grounds. Moreover, since all other models do not nest with each other, their mutual comparison cannot be achieved using usual statistical tools. For this reason, we will follow the simulation-based comparison approach advocated by Lo [2008].

The starting point of this approach is that the impulse response function (and hence the half-life) of a linear model can be thought of as a weighted average of the impulse response functions (or half-lives) obtained for various starting values and shock sizes from the nonlinear model, assuming the latter is the true DGP ${ }^{3}$. The average IRF obtained from a large set of different starting values and shock sizes corresponds to the unconditional version of the so-called Generalized IRF (hereafter GIRF) first introduced by Koop et al. [1996]. Put in other words, the linearly generated IRF for a nonlinear process should capture the unconditional GIRF and hence, the difference between these two measures - or the mean bias in Lo [2008]'s terminology — should be zero. So as to illustrate this point, let us

\footnotetext{
${ }^{3}$ See also Bec et al. [2010] on this point.
} 
consider the following SETAR process:

$$
\Delta y_{t}=s_{t}(-0.13) y_{t-1}+\varepsilon_{t}
$$

with $s_{t}=1_{\left|y_{t-1}\right|>\lambda}$ for $\lambda>0$. Then, denoting by $\delta$ the initial shock, the IRF at horizon $k$ conditionally on $s_{t}=1$ is given by $0.87^{k} \delta$, whereas it is $1^{k} \delta$ conditionally on $s_{t}=0$. By contrast, if a linear autoregression is mistakenly estimated for the process described in equation (7), then the estimated autoregressive coefficient, say $\phi$, will be such that $-0.13<\phi<0$. Consequently, the linear, symmetric and history-independent IRF from this linear model ${ }^{4}$, given by $(1+\phi)^{k} \delta$ will be larger than $0.87^{k} \delta$, but smaller than $1^{k} \delta$ for each $k$.

The GIRF is introduced by Koop et al. [1996] to handle the issues involved by defining impulse response function for nonlinear models. The GIRF for a univariate model is defined as the difference between two expected series of the variable, conditional on different assumptions on (i) history $\boldsymbol{\Theta}=\left(\theta_{t-p}, \theta_{t-p+1}, \ldots, \theta_{t-1}\right)$, (ii) $\operatorname{shock}(\mathrm{s})$ of interest $\boldsymbol{\Delta}=\left(\delta_{t}, \delta_{t+1}, \ldots, \delta_{t+k}\right)$ and (iii) randomized shocks $\boldsymbol{V}=$ $\left(\nu_{t}, \nu_{t+1}, \ldots, \nu_{t+k}\right)$. Given a general nonlinear model $y_{t}=g\left(\overline{\boldsymbol{y}_{\boldsymbol{p}}}, \varepsilon_{t}\right)$ where $\overline{\boldsymbol{y}}_{\boldsymbol{p}}=$ $\left(y_{t-p}, y_{t-p+1}, \ldots, y_{t-1}\right)$, the generalized impulse response function can be defined as:

$$
\begin{aligned}
& G I R F_{y}(k, \boldsymbol{V}, \boldsymbol{\Delta}, \boldsymbol{\Theta})= \\
& \quad E\left(y_{t+k} \mid \overline{\boldsymbol{y}}_{\boldsymbol{p}}=\boldsymbol{\Theta}, \varepsilon_{t}=\nu_{t}+\delta_{t}, \varepsilon_{t+1}=\nu_{t+1}+\delta_{t+1}, \ldots, \varepsilon_{t+k}=\nu_{t+k}+\delta_{t+k}\right) \\
& -E\left(y_{t+k} \mid \overline{\boldsymbol{y}}_{\boldsymbol{p}}=\boldsymbol{\Theta}, \varepsilon_{t}=\nu_{t}, \varepsilon_{t+1}=\nu_{t+1}, \ldots, \varepsilon_{t+k}=\nu_{t+k}\right) .
\end{aligned}
$$

In order to compare the results between the linear and nonlinear results, Lo [2008] assumes the true DGP is non linear and simulate both a nonlinear and a linear IRF based on the same shocks $\Delta$. From these simulated IRFs, he then defines the mean bias in the impulse responses due to model mis-specification as:

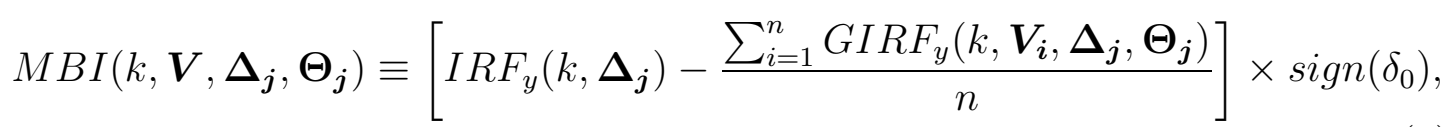

where $\boldsymbol{\Delta}_{j}$ and $\boldsymbol{\Theta}_{j}$ are the $j$ th set of shocks of interest and history drawn from specific distributions. $\operatorname{IRF}_{y}\left(k, \boldsymbol{\Delta}_{\boldsymbol{j}}\right)$ is the linear IRF, which is randomized shocks

\footnotetext{
${ }^{4}$ The IRFs from linear models are based on the full sample information and as such are unconditional.
} 
and history independent. $G I R F_{y}\left(k, \boldsymbol{V}_{\boldsymbol{i}}, \boldsymbol{\Delta}_{\boldsymbol{j}}, \boldsymbol{Y}\right)$ is the GIRF associated with the relevant randomized shocks, shocks of interest and history. So, the second term on the right hand side is the mean of the $n$ simulated nonlinear GIRFs with fixed $\Delta_{j}$ and $Y_{j}$ but randomized $V_{i}$, where $i$ denotes the sub-trial in KPP's nonlinear IRF simulation within each Monte Carlo simulation trial. The right hand side of equation (9) is finally multiplied by the sign of the shock of interest in order to avoid fallacious inference regarding the sign of this mean bias: indeed, the shock might be positive or negative. In each $j$ trial, $\overline{\boldsymbol{y}}_{p}$ is first drawn randomly from the observations. Then, for the discontinuous nonlinear models, a regimespecific initial shock $\delta_{0}$ is drawn while $\delta_{t+k}=0$ for all $k \geq 1$. For the smooth transition models, the initial shock is drawn from the full sample distribution of the estimated residuals. The randomized shocks $\nu_{t}$ 's are drawn accordingly, i.e. in a regime-specific way for discontinuous models and from the full sample otherwise.

To illustrate this, Figure 1 reports GIRFs confidence intervals - $\left[G I R F_{k, 1 \%}\right.$,

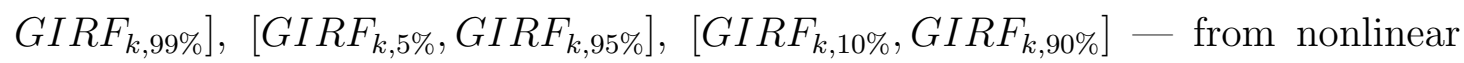
models (upper graph is for SETAR, the lower one is for ESTAR) and IRF from linear AR model when the true DGP is given by the SETAR model given in equation (7) with $\lambda=0.3$ and $\sigma=0.09$. Here, $i$ and $j$ are respectively set to 500 and 1,000. The mean $\overline{G I R F}_{k}$ corresponds to the dotted bold line while the IRF from the linear AR model is represented by the solid bold line. As clearly shown by the top panel of Figure 1, the confidence intervals of GIRFs from the SETAR model include the AR's IRFs. By contrast, the bottom panel in Figure 1 shows that the AR IRFs are out of the confidence intervals whatever the horizon $k$, as expected since the ESTAR model is wrongly used to model the dynamics of a SETAR process. Furthermore, it can be seen from Figure 2 that the mean bias confidence intervals based on the SETAR model always include zero (top panel), while they do not when based on the ESTAR model (bottom panel). 

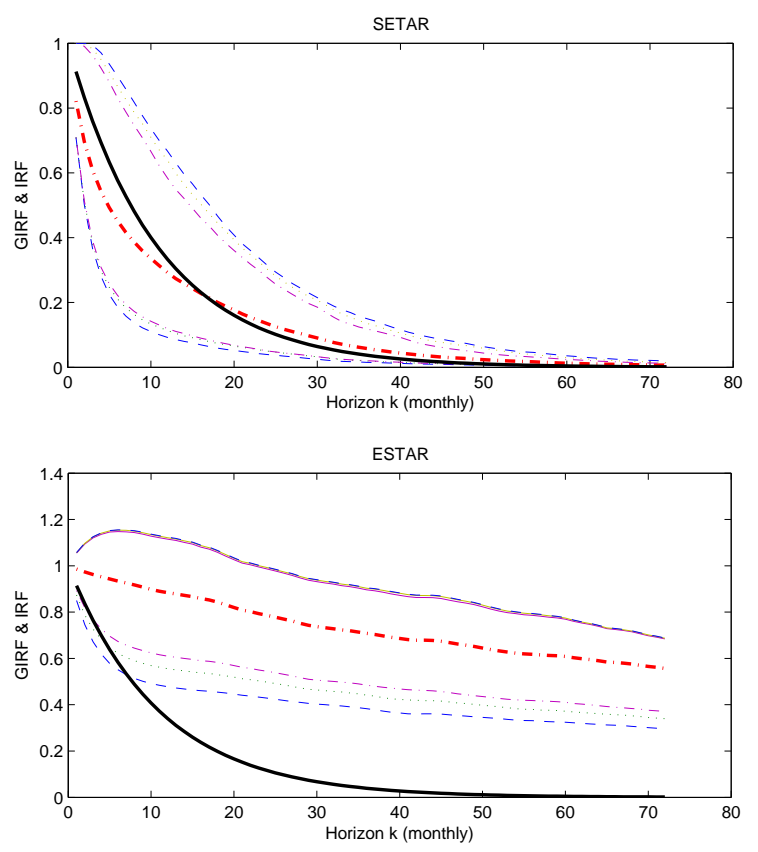

Figure 1: GIRF and IRF
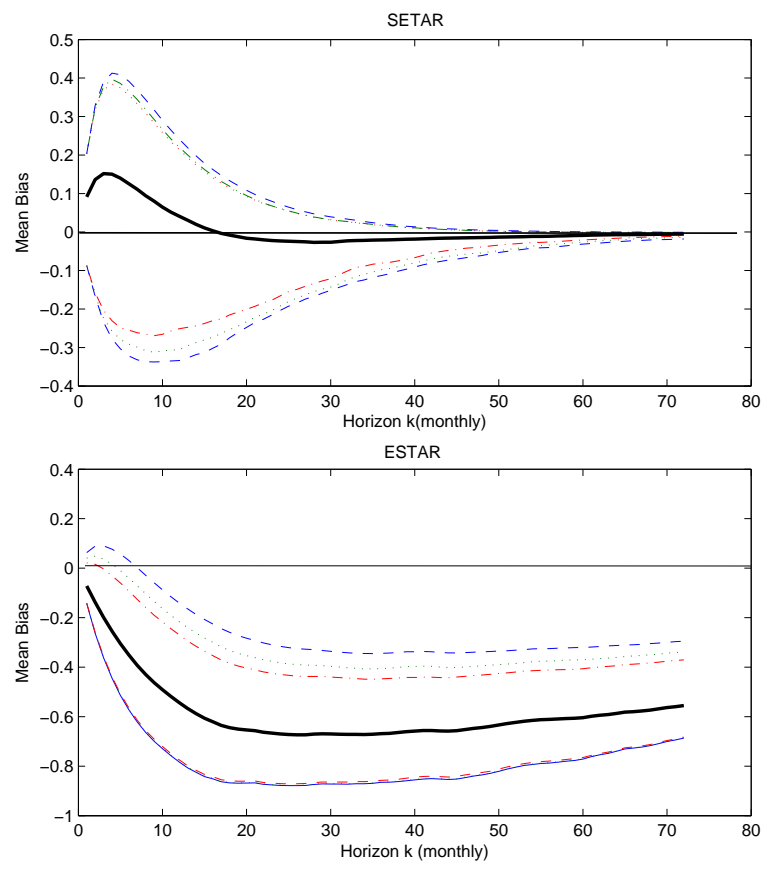

Figure 2: Mean Bias 


\section{Empirical Results}

\subsection{The data}

Our data set comprises monthly observations spanning 1970:01 to 2010:04 ${ }^{5}$ for eight bilateral exchange rates vis-a-vis the US Dollar, including the five founding countries of the ASEAN, the so-called ASEAN-5, namely Indonesia, Malaysia, the Philippines, Singapore and Thailand. For comparison sake, the three countries adding up to the ASEAN so as to form the so-called ASEAN Plus Three are also considered, namely Japan, Hongkong China ${ }^{6}$ and South Korea. These two sets of exchange rates aim at checking whether it makes a difference in the real exchange rate dynamics to be an 'old' ASEAN member (the ASEAN-5 was formed in 1967) or a 'young' cooperator (the "Plus Three" first meeting took place in 1997). The logarithm of the real exchange rate, $y_{t}$, is calculated as $y_{t}=\ln \left(S_{t}\right)+\ln \left(P_{t}^{*}\right)-\ln \left(P_{t}\right)$, where $S_{t}$ is the nominal exchange rate defined as the price of foreign currency in terms of home currency, $P_{t}$ is the domestic price level, and $P_{t}^{*}$ is the price level of the foreign country. All the data come from the IMF' International Financial Statistics. The domestic and foreign price series are based on the consumer price index. The U.S. is chosen as the foreign country. The log of the eight real exchange rates in terms of the U.S. dollar are plotted in Figure 5 in the Appendix.

\subsection{Preliminary unit root and linearity tests}

As stressed in e.g. Bec et al. [2004], the first two stepsin nonlinear time series modelling are $i$ ) unit root testing and $i$ ) linearity testing, because the distribution of the latter requires the series to be stationary. In Table 1 below, we report the standard ADF unit root test as well as the Kapetanios et al. [2003] (KSS), Bec et al. [2010] SupLR (BBC) and Bec et al. [2008a] unbounded SupWald (BGG) unit root tests. For each series, the models include as many autoregressive lags, namely $p$ in equation (1), as needed to get rid of serial correlation in the model under the null. For the three tests considering a nonlinear stationary alternative, the log of

\footnotetext{
${ }^{5}$ Our sample includes some relevant events like the 1997 Asian financial crisis and the 2008 global sub-prime crisis.

${ }^{6}$ For HongKong, the data are available from 1980:10 only.
} 
the real exchange rates are centered. The last column of Table 1 reports, for those series rejecting the unit root null in the first step, the Lagrange Multiplier linearity test (LML) derived in Bec et al. [2010] against the general MR-LSTAR alternative which is $\chi^{2}(2)$ distributed under the null. Whereas the ADF test fails to reject the

Table 1: Unit root and linearity tests

\begin{tabular}{lcccccc}
\hline \hline \multirow{2}{*}{ Real Exchange Rate } & \multicolumn{6}{c}{ US dollar based } \\
\cline { 2 - 7 } & $p$ & ADF & KSS & BBC & BGG & LML \\
\hline Indonesia & 5 & -1.59 & $-4.70^{* * *}$ & $55.36^{* * *}$ & $61.68^{* * *}$ & $34.34^{* * *}$ \\
Malaysia & 8 & -0.85 & -2.48 & $44.26^{* * *}$ & $42.12^{* * *}$ & $30.58^{* * *}$ \\
Philippines & 1 & -2.34 & -1.36 & 7.92 & $14.24^{* *}$ & $4.61^{*}$ \\
Singapore & 1 & -2.17 & -2.38 & 5.86 & $13.11^{*}$ & 1.44 \\
Thailand & 5 & -1.71 & $-4.60^{* * *}$ & $64.74^{* * *}$ & $58.34^{* * *}$ & $42.91^{* * *}$ \\
& & & & & & \\
& & & & & & \\
Hongkong & & -0.82 & -1.08 & 6.05 & 3.84 & \\
Japan & 1 & $-2.64^{*}$ & -2.04 & 1.47 & 6.12 & \\
Korea & 5 & $-2.62^{*}$ & $-5.56^{* * *}$ & $32.34^{* * *}$ & $32.42^{* * *}$ & $33.20^{* * *}$ \\
\hline \hline
\end{tabular}

Superscripts $*, * *, * * *$ denote significance at the $10 \%, 5 \%$ and $1 \%$ levels respectively.

unit root null in all the cases, the KSS test, which is specifically built against an ESTAR alternative rejects it for Indonesia, Thailand and Korea. The BBC test, which considers a stationary MR-LSTAR under the alternative, rejects the null for the three latter, and also for Malaysia at the 5\% level. Finally, the BGG test which has power against any nonlinear alternative, the ACR one included, clearly supports the conclusions drawn by the BBC test regarding Indonesia, Malaysia, Thailand and Korea. On top of these, the null is rejected at the $5 \%$ level for the Philippines and at the $10 \%$ level for Singapore. As a matter of fact, these results reject the unit root for four (or five at the $10 \%$ level) out of the five countries belonging to the ASEAN-5, and only for one out of three other Asian countries. When looking at the last column, it appears that for all the stationary real exchange rates but the SGD one, the linear null is rejected, even though at the $10 \%$ 
only for the Philippines.

\subsection{Nonlinear models estimates}

Table 2 reports estimates from the nonlinear models. Panel (a) reports the estimates for the autoregressive coefficients. Panel (b) reports other estimates of interest. Even though the linearity null was not rejected for the SGD currency, we still consider Singapore throughout the empirical analysis on the basis of the BGG test results that the linear unit root model is rejected at the $10 \%$ level against a stationary nonlinear alternative. ${ }^{7}$ Accordingly, the corresponding results will be cautiously interpreted. The estimates from linear AR models suggest a high persistence in Asian real exchange rates dynamics, which is consistent to what Rogoff [1996] reports, i.e. the so-called PPP puzzle.

Let us first focus on the estimates of the four stationary and nonlinear RERs based on BGG and LML tests at the 5\%-level: Korea, Indonesia, Malaysia and Thailand RERs. From Table 2, it is worth noticing that the four nonlinear models considered here lead to the same conclusion for these countries. Actually, they all point to significantly negative values for the autoregressive parameter in the outer regime, $\phi_{1}$. In absolute value, the smallest one, -0.038 , is obtained for the Indonesian currency in the ESTAR model while the largest one, -1.299, is obtained for the Thailand Bath in the SETAR model. In most of these cases, the estimated parameter in the inner regime, $\hat{\phi}_{2}$, is not significantly different from zero with the noticeable exception of the ESTAR model where it is found significantly positive: this indicates an explosive dynamics herein which is compatible with a globally stationary process as soon as $-2<\phi_{1}<0$. To sum up, our results clearly support a nonlinear mean reverting dynamics for these four real exchange rates.

The null hypothesis unit root and/or linearity were not so strongly rejected for the two remaining currencies, namely PHP and SGD. It is worth noticing that the SETAR and ESTAR models estimates do not point to mean reversion in these cases, where $\hat{\phi}_{1}$ is not significantly different from zero. Regarding Philippines, this

\footnotetext{
${ }^{7}$ Actually, even though powerful, the Lagrange Multiplier linearity test may still fail to reject the null too often.
} 
Table 2: Estimation Results

Panel (a) Estimates for Autoregressive Coefficients

\begin{tabular}{c|cccccccccc}
\hline & $p$ & $\mathrm{AR}$ & \multicolumn{2}{c}{$\mathrm{SETAR}$} & \multicolumn{2}{c}{ ESTAR } & \multicolumn{2}{c}{ MR-LSTAR } & \multicolumn{2}{c}{ ACR } \\
& & $\phi$ & $\phi_{1}$ & $\phi_{2}$ & $\phi_{1}$ & $\phi_{2}$ & $\phi_{1}$ & $\phi_{2}$ & $\phi_{1}$ & $\phi_{2}$ \\
\hline \multirow{2}{*}{ Indonesia } & 5 & -0.007 & $\mathbf{- 0 . 4 6}$ & 0.002 & $\mathbf{- 0 . 0 3 8}$ & $\mathbf{0 . 0 4 1}$ & $\mathbf{- 0 . 3 6 5}$ & 0.002 & $\mathbf{- 0 . 2 4 6}$ & $\mathbf{0 . 0 0 9}$ \\
& & $(0.005)$ & $(0.073)$ & $(0.005)$ & $(0.009)$ & $(0.014)$ & $(0.048)$ & $(0.006)$ & $(0.015)$ & $(0.004)$ \\
Malaysia & 8 & -0.002 & $\mathbf{- 1 . 0 5}$ & 0.003 & $\mathbf{- 0 . 0 8 1}$ & $\mathbf{0 . 0 4 6}$ & $\mathbf{- 0 . 4 4 1}$ & -0.004 & $\mathbf{- 0 . 4 1 1}$ & 0.0005 \\
& & $(0.003)$ & $(0.173)$ & $(0.003)$ & $(0.017)$ & $(0.011)$ & $(0.086)$ & $(0.006)$ & $(0.027)$ & $(0.002)$ \\
Philippines & 1 & $\mathbf{- 0 . 0 1 7}$ & -0.033 & $\mathbf{- 0 . 0 5 1}$ & -0.004 & $\mathbf{- 0 . 0 8}$ & -0.066 & $\mathbf{- 0 . 0 5 1}$ & -0.004 & $\mathbf{- 0 . 0 5 1}$ \\
& & $(0.007)$ & $(0.056)$ & $(0.013)$ & $(0.007)$ & $(0.036)$ & $(0.067)$ & $(0.014)$ & $(0.008)$ & $(0.013)$ \\
Singapore & 1 & $\mathbf{- 0 . 0 1 2}$ & $\mathbf{- 0 . 0 7 5}$ & -0.005 & -0.041 & -0.003 & $\mathbf{- 0 . 1 9 3}$ & -0.014 & $\mathbf{- 0 . 0 8 9}$ & -0.006 \\
& & $(0.005)$ & $(0.150)$ & $(0.006)$ & $(0.044)$ & $(0.013)$ & $(0.074)$ & $(0.008)$ & $(0.045)$ & $(0.006)$ \\
Thailand & 5 & -0.008 & $\mathbf{- 1 . 2 9 9}$ & -0.001 & $\mathbf{- 0 . 1 2 6}$ & $\mathbf{0 . 0 4 9}$ & $\mathbf{- 0 . 6 4 9}$ & -0.004 & $\mathbf{- 0 . 4 8 9}$ & 0.001 \\
& & $(0.005)$ & $(0.113)$ & $(0.004)$ & $(0.026)$ & $(0.013)$ & $(0.078)$ & $(0.006)$ & $(0.026)$ & $(0.003)$ \\
\hline \multirow{2}{*}{ Korea } & 5 & $\mathbf{- 0 . 0 2 3}$ & $\mathbf{- 0 . 3 0 8}$ & 0.0009 & $\mathbf{- 0 . 1 8 4}$ & $\mathbf{0 . 0 3 5}$ & $\mathbf{- 0 . 3 4 5}$ & -0.036 & $\mathbf{- 0 . 1 5 9}$ & -0.001 \\
& & $(0.008)$ & $(0.080)$ & $(0.009)$ & $(0.041)$ & $(0.014)$ & $(0.073)$ & $(0.022)$ & $(0.022)$ & $(0.008)$ \\
\hline
\end{tabular}

Panel (b) Nonlinear Parameters Estimates

\begin{tabular}{c|cccccc}
\hline & SETAR & ESTAR & \multicolumn{2}{c}{ MR-LSTAR } & \multicolumn{2}{c}{ ACR } \\
& $\lambda$ & $\gamma$ & $\lambda$ & $\gamma$ & $\mathrm{a}$ & $\mathrm{b}$ \\
\hline Indonesia & 0.385 & 11.74 & 0.31 & 1167.06 & -12.72 & 16.83 \\
Malaysia & 0.181 & 21.99 & 0.16 & 87.97 & -49.73 & 106.22 \\
Philippines & 0.088 & 335.86 & 0.09 & 335.86 & -16387 & 55133 \\
Singapore & 0.09 & 49.82 & 0.07 & 298.74 & -29.07 & 87.59 \\
Thailand & 0.157 & 29.93 & 0.13 & 329.24 & -5.83 & 5.23 \\
\hline Korea & 0.108 & 42.12 & 0.086 & 58.97 & -51.59 & 150.23 \\
\hline \hline
\end{tabular}

1. Figures in bold indicate $5 \%$ significance level.

2. Standard errors into parentheses. 

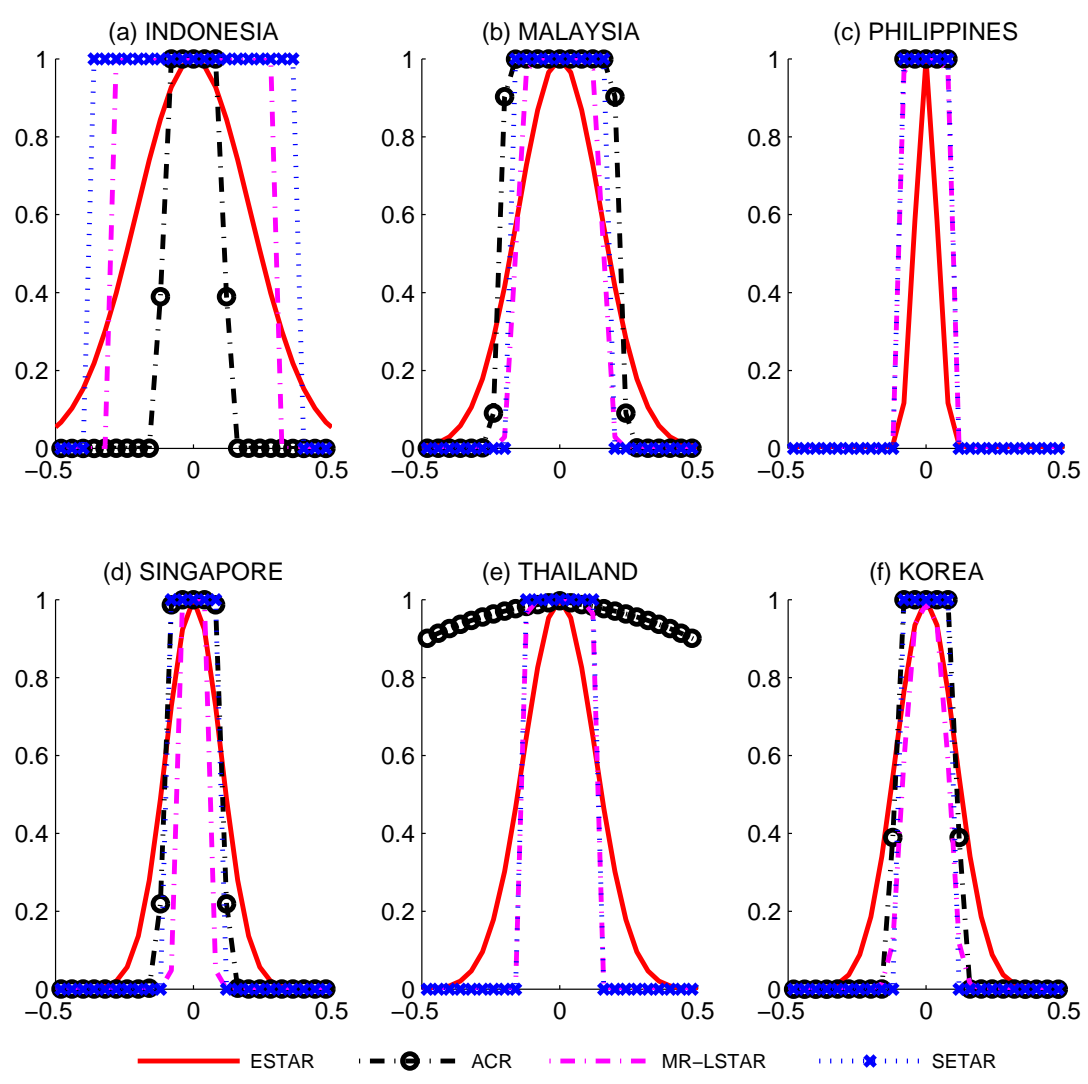

Figure 3: Estimated Transition Functions

is also the case for the MR-LSTAR and ACR models, even though $\hat{\phi}_{1}$ has the correct sign and $\left|\hat{\phi}_{1}\right|>\left|\hat{\phi}_{2}\right|$ according to the MR-LSTAR estimates. By contrast, these two models estimates suggest mean reversion in the SGD series, but a weaker one than for the four first cases considered. For Singapore, $\left|\hat{\phi}_{1}\right|$ is relatively small since it is -0.193 and -0.089 for the MR-LSTAR and ACR models respectively. Panel (b) of Table 2 reports the estimates of the threshold and speed parameters for the nonlinear models. Based on these estimates, the four transition functions of these six real exchange rates are drawn in Figure 3. The transition functions for the MR-LSTAR and ACR models look like step functions, except for the ACR in Thailand. Those for the ESTAR are smoother. As pointed out by Bec et al. [2010], for large values of the speed parameter $\gamma$, the MR-LSTAR and ESTAR transition 


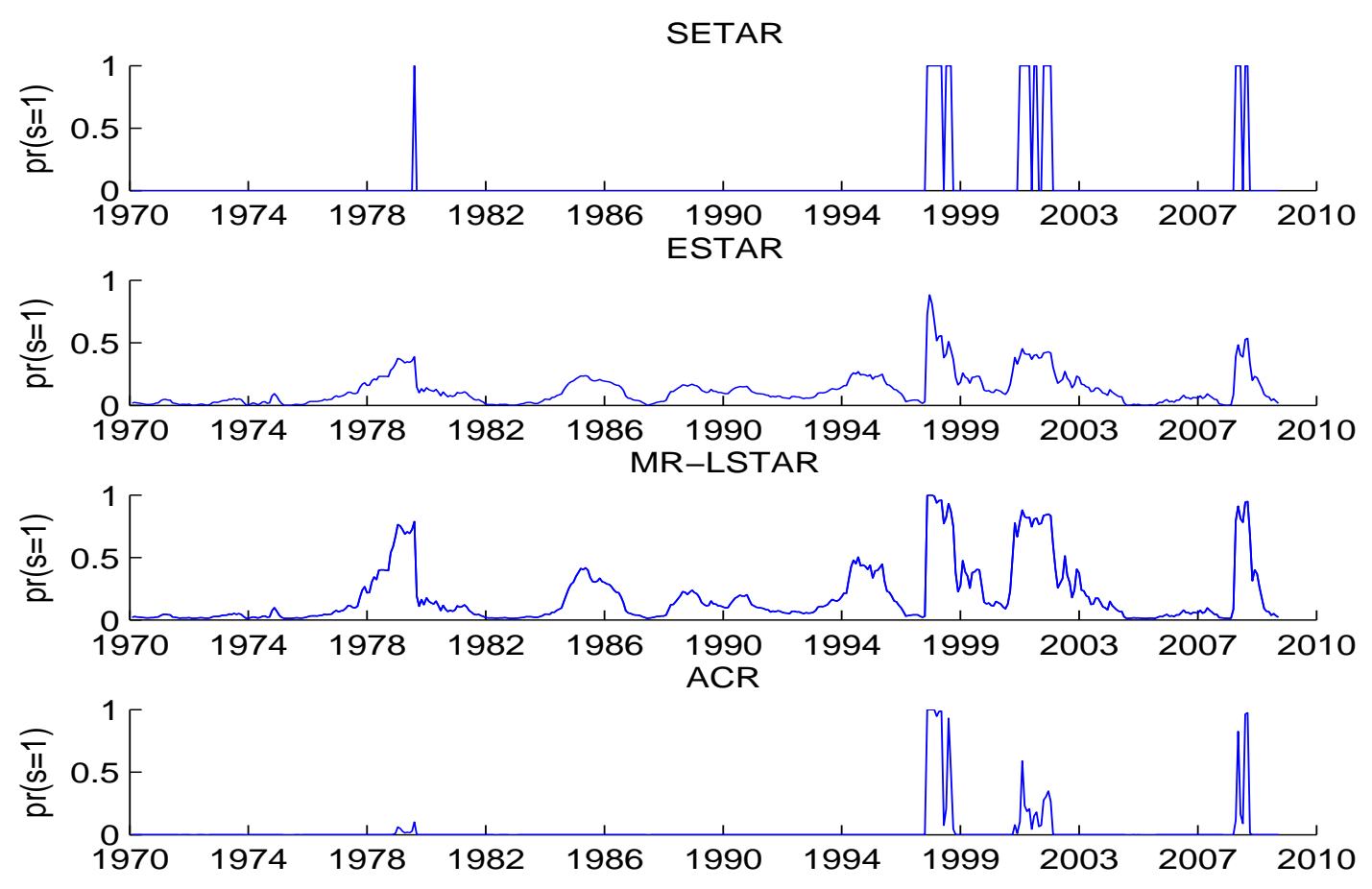

Figure 4: Probability to be in the outer regime for Korea

functions are quite different whereas they are similar for medium values. Consider Indonesia, where the largest $\hat{\gamma}$ is reached from MR-LSTAR estimates: the function of MR-LSTAR is similar to SETAR, but quite different from that of ESTAR.

To illustrate the relevance of such nonlinear dynamics, let us focus on the transition probabilities estimates for Korea, which has the most consistent estimates from all those nonlinear models. In Figure 4, MR-LSTAR, SETAR, ESTAR and ACR estimated probabilities to lie in the outer regime are plotted. By fitting a SETAR, we find a threshold of 0.107. The SETAR classification looks quite crude compared to the MR-LSTAR. The ESTAR transition probability is the smoothest one whereas the ACR transition probability tends to be more discontinuous and looks rather similar to the SETAR transition probability. According to Figure 4, the estimated conditional probability of KWR/USD to be in the outer regime peaks four times. The first peak observed around 1979 corresponds the second oil 
price shock. The largest peaks occuring between 1997 and 1998 reflect the huge impact of the Asian financial crisis: Thailand's sudden decision to float the Thai Baht on 2 July 1997 caused the Korean Won to depreciate rapidly. The Asian financial crisis broke out. Aiming to defend the local currency, the Korean government widened its Won trading band from 2.25\% to $10 \%$ on 19 November 1997, and finally abolished this band to allow the Won to freely float on 12 December 1997. The peak after the Asian financial crisis corresponds to the year when Korea adopted the policy of exchange liberalization in 2001. Actually, the 1997 IMF-led rescue package required Korea to commit itself to liberalizing all aspects of the foreign-exchange system by the end of 2001. The third peak observed between 2008 and 2009 reflects the large shock of current global financial crisis. The Korean financial market, which was exposed to foreign capital relatively more than other emerging markets, was affected more severely: the Won recorded the sharpest depreciation, while the plunge of Korean stock prices was just as bitter as other markets. The Bank of Korea consequently prepared and executed proposals for alleviating the factors causing financial market unrest and preventing the turmoil from evolving into a foreign currency crisis.

It is worth noting that it the estimated transition probabilities are rather flat before the 1997 Asian financial crisis. There are two reasons for this: first, from 1961 until 1980 the Korean government strictly regulated foreign currency transactions, and the Korean Won was pegged to the U.S dollar. From 1980 until 1997 Korean government introduced a multiple-basket pegged exchange rate system which was still tightly managed by the government; second, the export-driven policy adopted by Korea leads to the close relationship between Korean economy and U.S economy. As can be seen from the Figure 4, the Korea Won has come back to the inner regime after the 2008 subprime crisis according to our estimated transition probabilities.

Finally, the results above suggest a nonlinear mean reverting dynamics for Indonesia, Malaysia, Thailand, Korea and, to a lesser extent Singapore. Regarding Philippines, where the unit root is rejected at the 5\%-level by the BGG test and the linearity is rejected at the $10 \%$-level according to the LML test, none of the 
four nonlinear models considered here seems to be able to capture suitably its nonlinear stationary dynamics. The subsequent analysis will nevertheless keep these six real exchange rates under scrutiny: so far, Singapore and Philippines results are mitigated and hence require further evidence.

\subsection{Comparison Based on General Impulse Responses Func- tion}

The next natural question to raise now is which nonlinear model would be the most likely true DGP. The objective of this section is to identify which model is compatible with the true DGP property discussed earlier: the impulse response mean bias confidence interval must contain zero. It worth noting that the estimates for $\phi$ in the linear AR model lies in the interval $\left(\hat{\phi}_{1}, \hat{\phi}_{2}\right)$ obtained from all the nonlinear models. In the Monte Carlo experiment for the mean bias computation, the total number of simulations $j$ is set to 5,000 and the number of replications for nonlinear impulse responses $i$ is set to 500. First, each of the nonlinear models is estimated for each real exchange rate. Then, the estimated coefficients and the distribution of the estimated residuals are used as the true parameters and the true distribution for the simulation. Then, in each trial, the simulated data are estimated by the true nonlinear and the incorrect AR model. The linear and nonlinear IRFs are finally generated so as to compute the mean bias. A six-year horizon (72 months) is retained for the IRFs simulation. The mean $\overline{M B I_{k}}$, and the two confidence intervals considered by Lo [2008] - $\left[M B I_{k, 16 \%}, M B I_{k, 0.84 \%}\right]$ and $\left[M B I_{k, 5 \%}, M B I_{k, 95 \%}\right]$ - are plotted for the four models in Figures 6, 7, 8 and 9 reported in the Appendix.

Results shown in Figures 7 and 8 support the assumptions that the ESTAR and MR-LSTAR models are the true DGPs for our panel of Asian real exchange rates: the mean bias confidence intervals include zero for all these 72-month horizons, with the only exception of the ESTAR for Philippines. Note that for the latter, the largest (in absolute value) outer regime parameter estimate $\hat{\phi}_{1}=-0.066$ was found for the MR-LSTAR model, but was not significantly different from zero at conventional level. It seems that despite this lack of accuracy in this parameter 
estimate from observed data, the MR-LSTAR is nevertheless compatible with the true DGP property under consideration here. Consequently, the large half-lives estimated from linear models are most likely generated by the omission of such kinds of nonlinear dynamics. Moreover, it makes sense that these two models are simultaneously successful regarding the true DGP criterium, as the ESTAR is a special case of the MR-LSTAR. By contrast, results in Figures 6 and 9 suggest that it is unlikely that the SETAR and ACR models are the true DGPs, as their mean bias confidence intervals do not contain zero for most cases.

\section{Conclusion}

Our empirical results provide evidence of nonlinear mean reverting dynamics for the Asian-5 real exchange rates since the early seventies. The estimated models imply an equilibrium level of the real exchange rate in the neighborhood of which the behavior of the log-level of the real exchange rate is close to a random walk, becoming increasingly mean reverting with the absolute size of the deviation from equilibrium.

While the ADF test fails to reject the null of a unit-root for all of the exchange rates at the $5 \%$ level, unit-root tests against a nonlinear stationary alternative reject the null for four pairs out the five ASEAN-5 group at the 5\% level and all of them at the $10 \%$ level. By contrast, only one pair out of the 'Plus Three' group rejects the unit root null. For these nonlinear stationary series, the estimation results support the PPP hypothesis by exhibiting strong mean reversion for large PPP departures. This finding may indeed be related to the close trade links between ASEAN and the US.

Finally, this paper applies the GIRF Monte Carlo experiment designed by Lo [2008] to compare the nonlinear model candidates. It turns out that the MRLSTAR and ESTAR models are the most likely DGPs. Using US-G6 real exchange rates, Lo [2008] results also point to the MR-LSTAR kind of dynamics. 


\section{References}

Aggarwal, R., A. Montanes, and M. Ponz, Evidence of long-run power parity: analysis of real Asian exchange rates in terms of the Japanese yen, Japan and the World Economy, 2000, 12, 351-361.

Balke, N.S. and T.B. Fomby, Threshold cointegration, International Economic Review, 1997, 38, 627-45.

Bec, F., A. Guay, and E. Guerre, Adaptive consistent unit root tests based on autoregressive threshold model, Journal of Econometrics, 2008, 142, 94-133.

A. Rahbek, and N. Shephard, The Autoregressive Conditional Root (ACR) Model, Oxford Bulletin of Economics and Statistics, 2008, 70 (5), 583-618.

_ _ and _ _ Vector Equilibrium Correction Models with Non-Linear Discontinuous Adjustments, Econometrics Journal, 2004, 7, 1-24.

_ _ , M. Ben Salem, and M. Carrasco, Test for Unit-root Versus Threshold Specification with an Application to the PPP, Journal of Business and Economic Statistics, 2004, 22, 382-395.

$\ldots$ _ $\ldots$, and __ Detecting Mean Reversion in Real Exchange Rates from a Multiple Regime Star Model, Annals of Economics and Statistics, 2010, 99/100, 35-428.

Berka, M., General Equilibrium Model of Arbitrage Trade and Real Exchange Rate Persistence, Manuscript, University of British Columbia 2004.

Choi, D.-Y., B.-H. Kim, and S.-W. Kim, Nonlinear Mean-Reversion in Southeast Asian Real Exchange Rates, Applied Financial Economics, 2011, 29 (19), 1409-1421.

Dumas, B., Dynamic equilibrium and the real exchange rate in a spatially separated world, Review of Financial Studies, 1992, 5 (2), 153-80. 
Enders, W. and C.W.J. Granger, Unit-root tests and asymmetric adjustment with an example using the term structure of interest rates, Journal of Business and Economic Statistics, 1998, 16 (3), 304-11.

Kapetanios, G., Y. Shin, and A. Snell, Testing for a unit root in the nonlinear STAR framework, Journal of Econometrics, 2003, 112 (2), 359-379.

Kilian, L. and M. Taylor, Why Is It So Difficult to Beat the random Walk Forecast of Exchange Rates ?, Journal of International Economics, 2003, 60 (1), 85107.

Kim, B.-H., H.-G. Kim, and K.-Y. Oh, Purchasing power parity in southeast Asian currencies:A time-varying coefficients approach, Econometic Modelling, 2009, 26 (1), 96-109.

Koop, G., M. Pesaran, and S. Potter, Impulse response analysis in nonlinear multivariate models, Journal of Econometrics, 1996, 74, 119-147.

Liew, V., A. Baharumshah, and T. Chong, Are Asian real exchange rates stationary?, Economics Letters, 2004, 83, 313-316.

Lo, M. C., Nonlinear PPP deviations: a Monte Carlo investigation of their unconditional half-life, Studies in Nonlinear Dynamics and Econometrics, 2008, $12(4)$.

and E. Zivot, Threshold Cointegration and Nonlinear Adjustment to the Law of One Price, Macroeconomic Dynamics, September 2001, 5 (4).

Michael, P., A. Nobay, and D. Peel, Transactions costs and nonlinear adjustment in real exchange rates : an empirical investigation, Journal of Political Economy, 1997, 105 (4), 862-79.

Obstfeld, M. and A. Taylor, Nonlinear Aspects of Goods-Market Arbitrage and Adjustment: Heckscher's Commodity Points Revisited, Journal of the Japanese and International Economies, 1997, 11, 441-479. 
and K. Rogoff, The Six Major Puzzles in International Macroeconomics : Is There a Common Cause ?, NBER Macroeconomics Annual, 2000, 15.

Park, J. and M. Shintani, Testing for a Unit Root against Transitional Autoregressive Models, Manuscript, 2005.

Rogoff, K., The purchasing power parity puzzle, Journal of Economic Literature, 1996, 34, 647-68.

Sercu, P., R. Uppal, and C. Van Hulle, The exchange rate in the presence of transaction costs : implications for tests of purchasing power parity, The Journal of Finance, 1995, 50 (4), 1309-19.

Taylor, M., D. Peel, and L. Sarno, Non-linear mean reversion in real exchange rates: Towards a solution to the PPP puzzles, International Economic Review, 2001, 42, 1015-1042.

Wu, J.-L., L.-J. Tsai, and S.-L. Chen, Are real exchange rates non-stationary? the Pacific Basin perspective, Journal of Asian Economics, 2004, 15 (2), 425-438.

Zurbruegg, R. and L. Allsopp, Purchasing power parity and the impact of the East Asian currency crisis, Journal of Asian Economics, 2004, 15, 739-758. 


\section{Appendix}
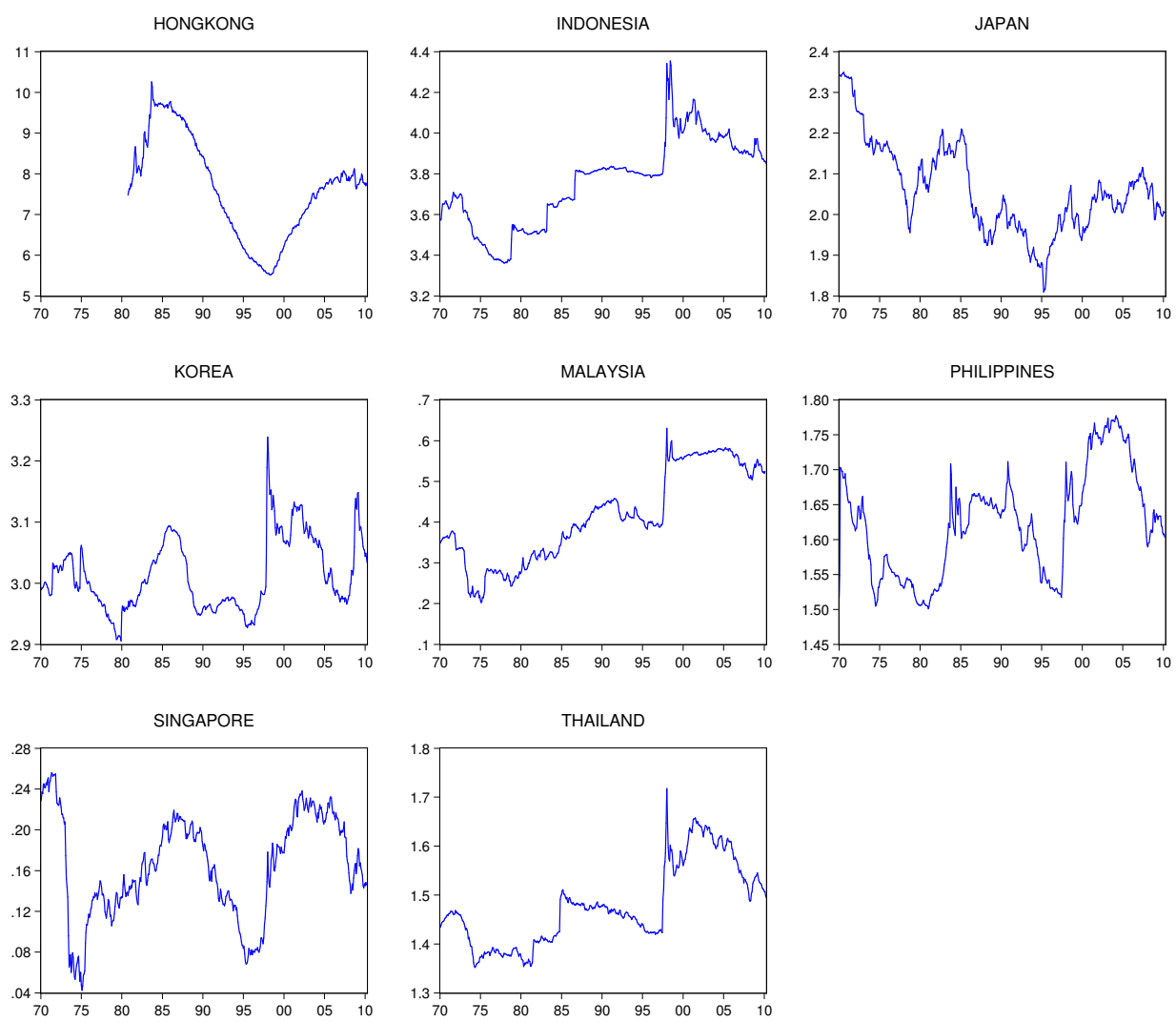

Figure 5: Real exchange rates in terms of the US Dollar (in logs) 


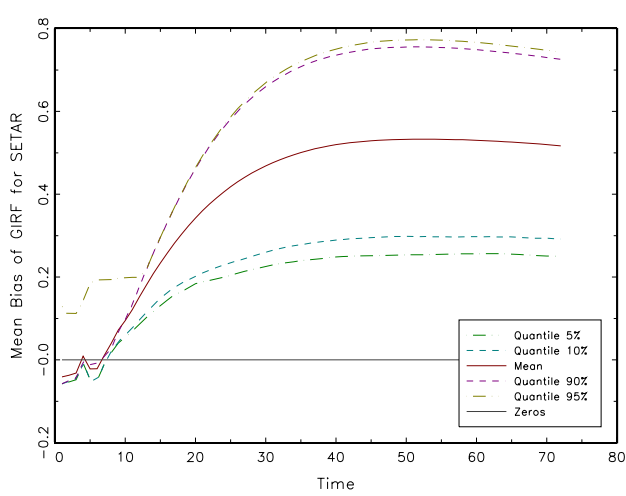

(a) Indonesia

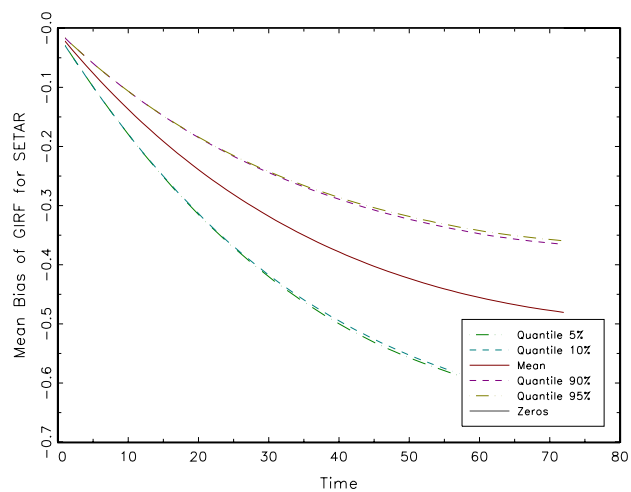

(c) Philippines

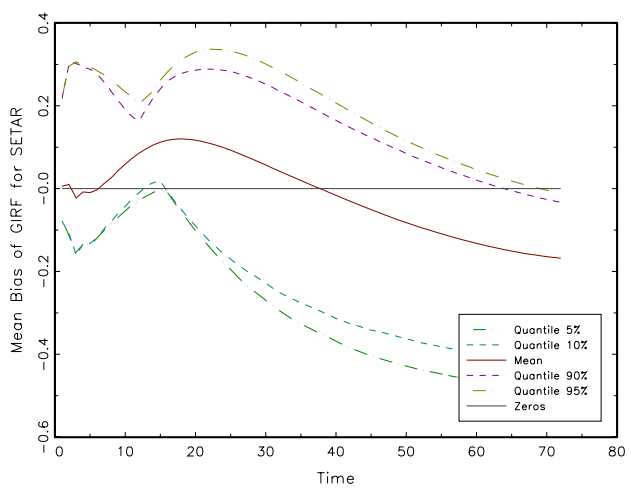

(e) Thailand

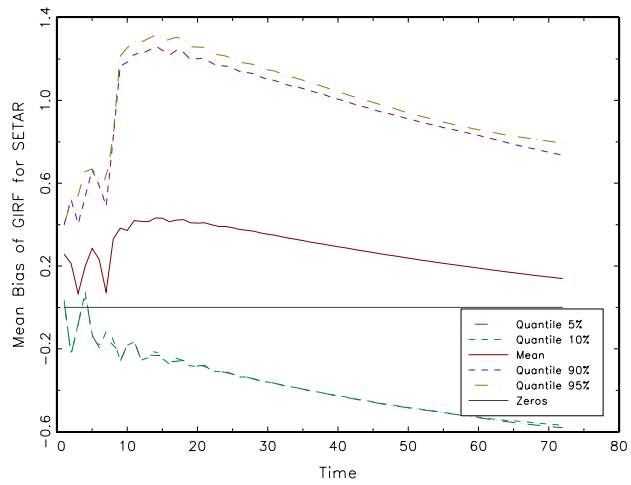

(b) Malaysia

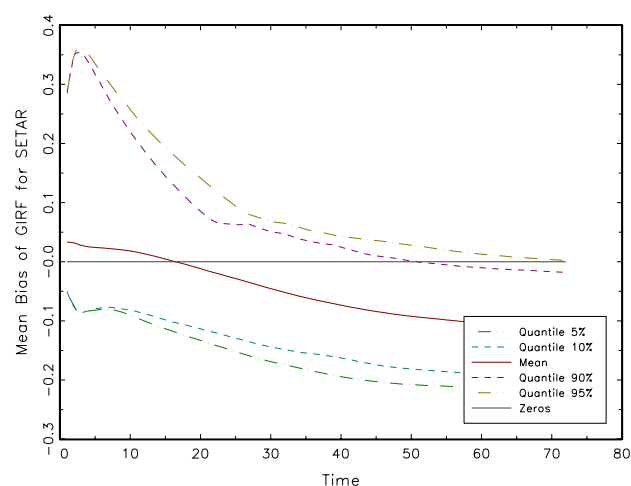

(d) Singapore

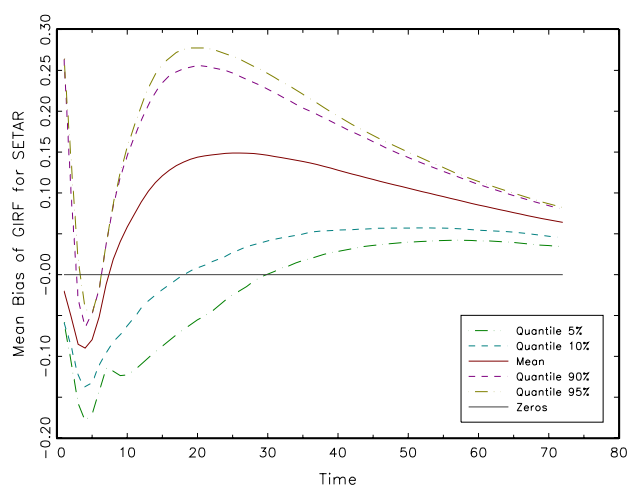

(f) Korea

Figure 6: Mean Bias of GIRF for SETAR 


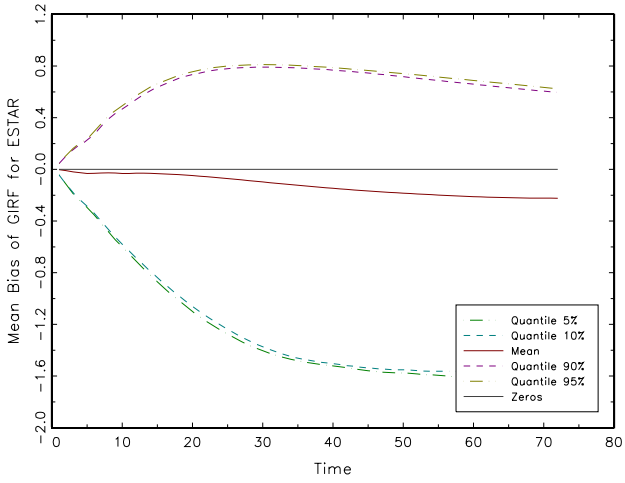

(a) Indonesia

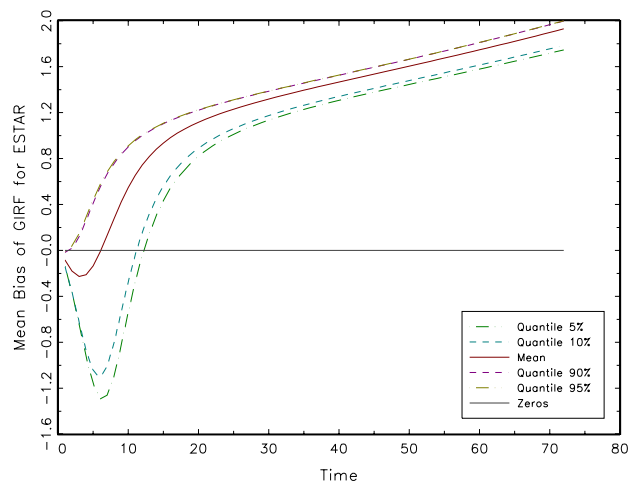

(c) Philippines

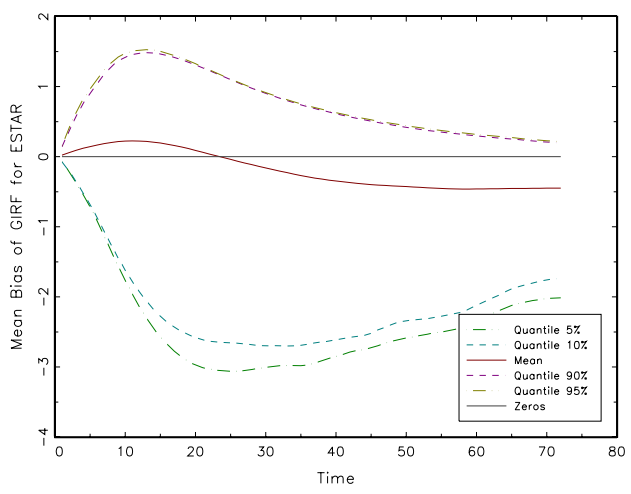

(e) Thailand

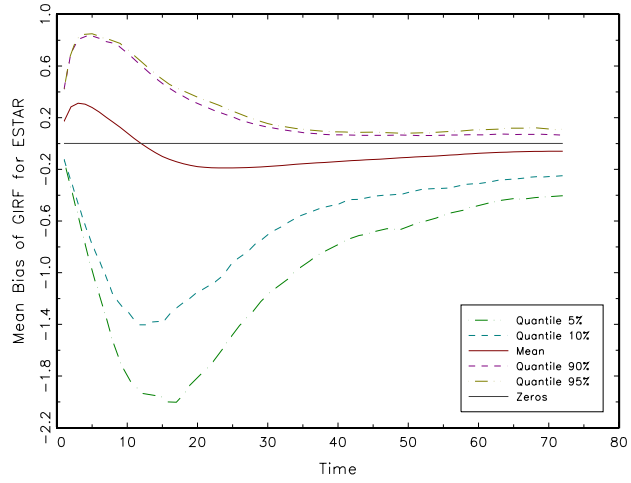

(b) Malaysia

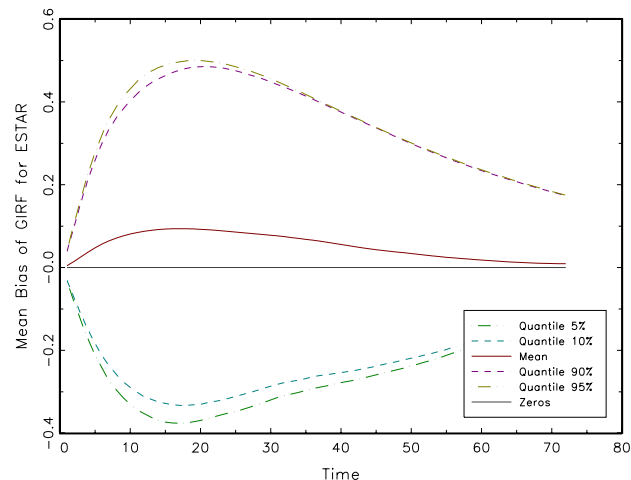

(d) Singapore

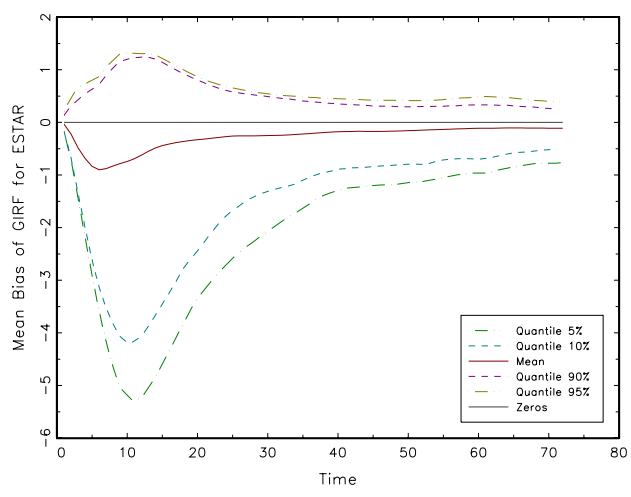

(f) Korea

Figure 7: Mean Bias of GIRF for ESTAR 


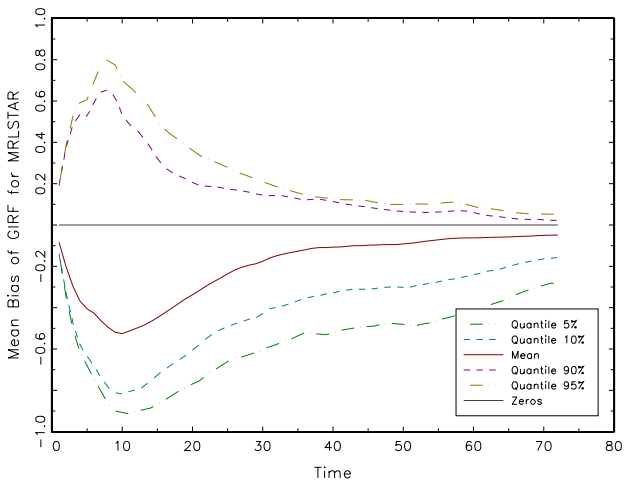

(a) Indonesia

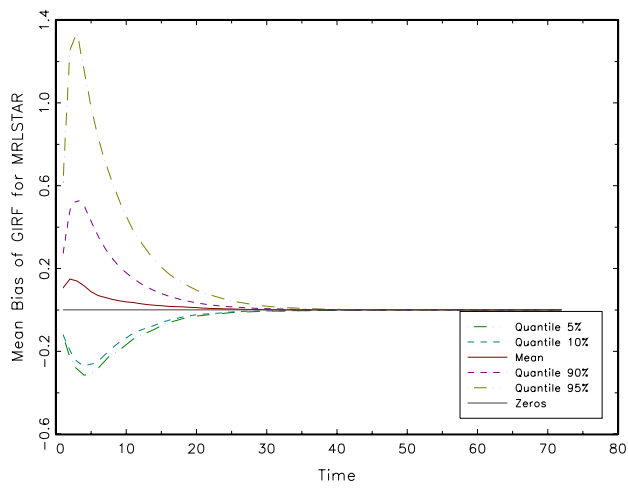

(c) Philippines

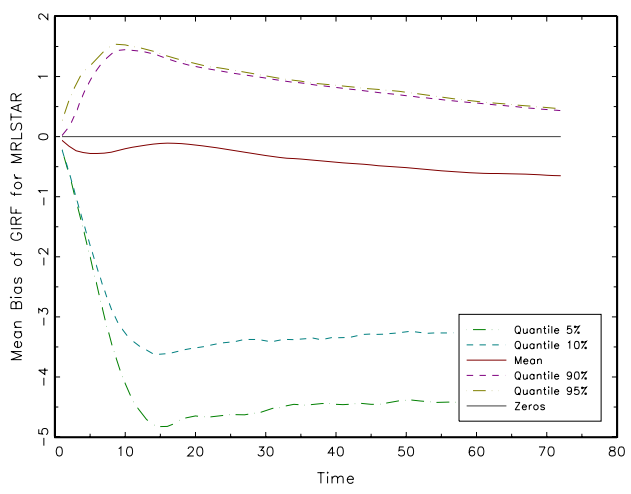

(e) Thailand

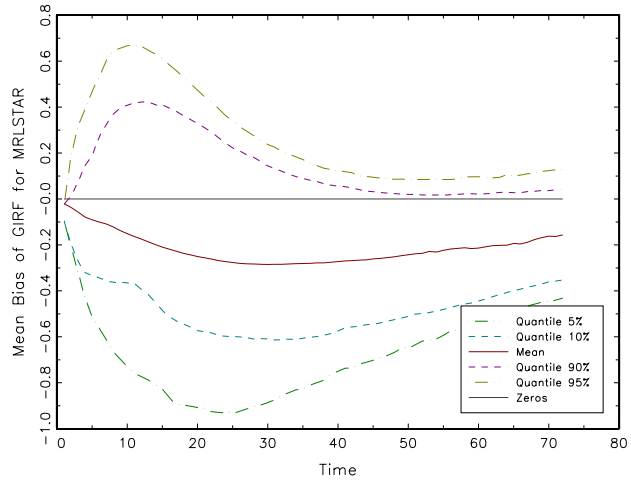

(b) Malaysia

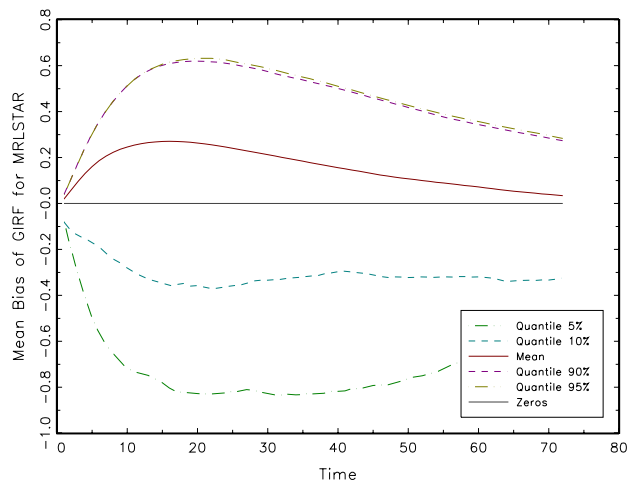

(d) Singapore

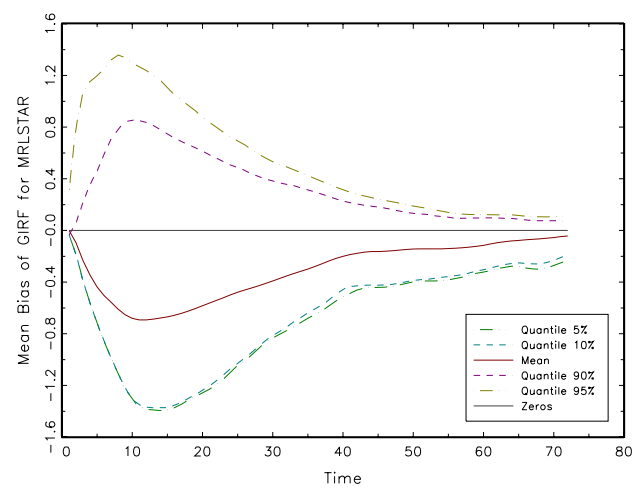

(f) Korea

Figure 8: Mean Bias of GIRF for MR-LSTAR 


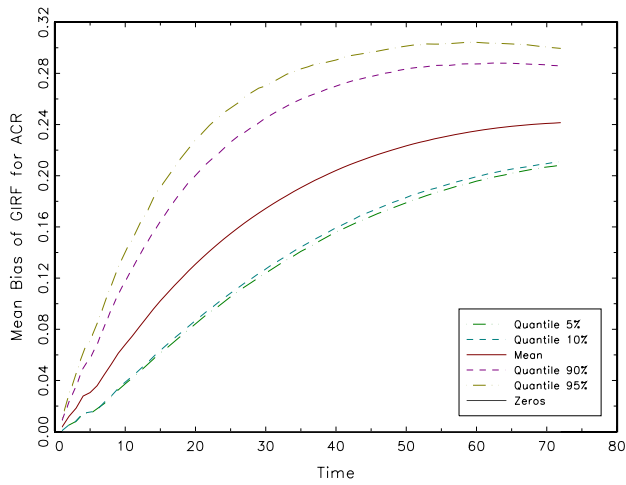

(a) Indonesia

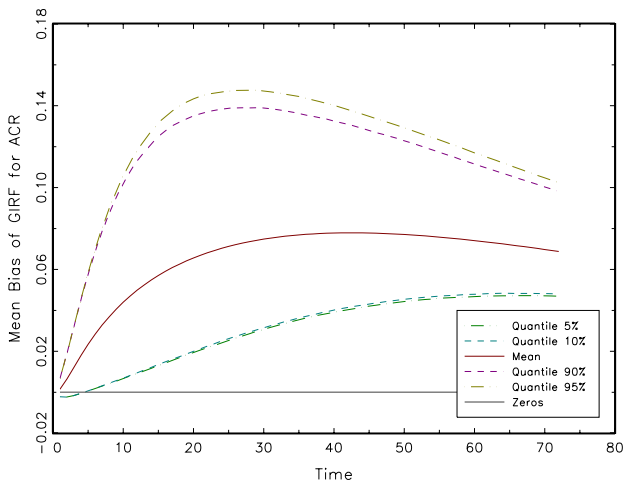

(c) Philippines

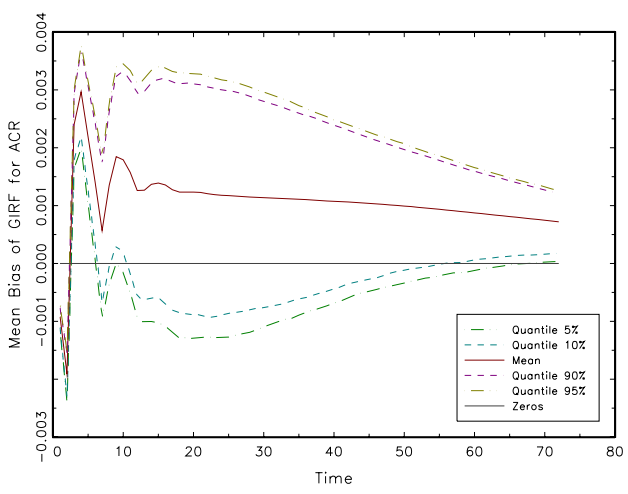

(e) Thailand

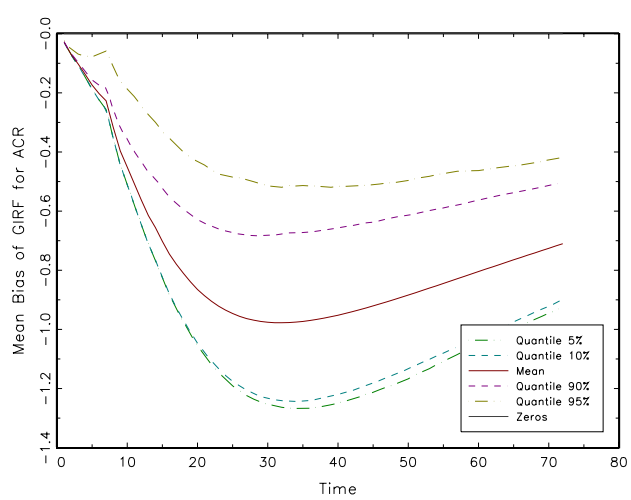

(b) Malaysia

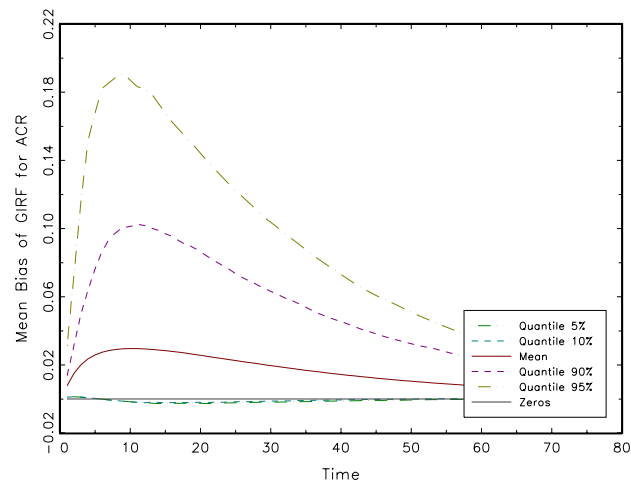

(d) Singapore

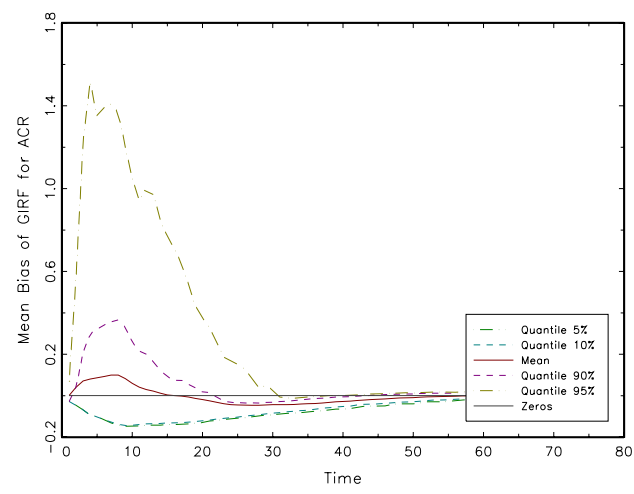

(f) Korea

Figure 9: Mean Bias of GIRF for ACR 